\title{
NUMERICAL INVESTIGATION OF THERMAL MANAGEMENT OF SOLID OXIDE FUEL CELLS BY FLOW ARRANGEMENT
}

\author{
Firat Sen and Ilker Tari* \\ Dept. of Mechanical Engineering, Middle East Technical University, Ankara, Turkey \\ *Correspondence author. Fax:+90 3122102536 Email: itari@metu.edu.tr
}

\begin{abstract}
Solid Oxide Fuel Cells (SOFCs) are electrochemical cells working at high temperatures. One of the important problems in planar SOFC designs is the non-uniform temperature distribution on the plane of the cell due to the waste heat produced by electrochemical reactions. Another important problem of SOFCs is the low fuel utilization ratio. In this study, the effect of the flow arrangement on the temperature distribution, which causes the thermal stresses, and the method to increase the fuel utilization, is numerically investigated. An SOFC single cell experimental setup is developed with the cross-flow arrangement. This setup and experimental conditions are modelled with ANSYS Fluent. The cross-flow experimental results are used in order to validate and verify the model. The validated model is used as a reference to develop the models for different flow arrangements and to investigate the effect of the flow arrangement on the temperature distribution. The simulation results are compared, in order to determine the best flow arrangement. Additionally, by using the simulation results, a method to increase the SOFC fuel utilization is suggested.
\end{abstract}

Suggested Keywords: Fuel Cells; Thermal Management; CFD; SOFC; Fuel utilization; Hydrogen energy 